\title{
MODELI, RAZINE I OBLICI KOMUNICIRANJA MEDICINSKOG OSOBLJA I PACIJENTA
}

\author{
Sandra Karabatić, Tanja Zovko, Latinka Basara \\ Klinika za plućne bolesti Jordanovac, KBC Zagreb, 10000 Zagreb, Hrvatska \\ Rad je primljen 17.2.2018. Rad je recenziran 29.2.2018. Rad je prihvaćen 8.3.2018.
}

\section{SAŽETAK}

Složen odnos između pacijenta i medicinskog osoblja ima svoju dugu povijest. Odnos pacijenta i medicinskog osoblja, posebno odnos pacijenta i liječnika tema je koja zaokuplja sve više pozornost teoretičara, istraživača i praktičara. Ovom problemu i temi pristupaju i zdravstveni djelatnici ali i komunikacijski stručnjaci. Obzirom na različita znanstvena područja kojima pripadaju zdravstvo i komunikacija ova tema postala je interdisciplinarna odnosno postoji potreba sagledavanja problematike iz perspektive najmanje dva znanstvena područja. Komunikacijski aspekt tih odnosa danas određuje kvalitetu i zdravstvene njega ali i konačnog ishoda liječenja. Poseban aspekt rada posvećen je in concreto komunikaciji medicinskog osoblja s pacijentima ali i drugim stakeholderima koji su od iznimne važnosti za razumijevanje ovog složenog procesa ali i uspjeha komunikacije. Medicinsko osoblje u ovom radu bit će u užem smislu definirano kao medicinske sestre. Upravo njihov odnos s pacijentima je središnji dio rada. Cilj rada je analizirati razine, oblike i modele komuniciranja medicinskog osoblja s pacijentom ali i drugim ciljnim javnostima ili dionicima.

Ključne riječi: komunikacija, modeli i oblici komuniciranja, medicinsko osoblje, pacijent

Osoba za razmjenu informacija:

Sandra Karabatić, MSN.BSN.RN

E- adresa: udruga.jedra@gmail.com

\section{UVOD}

Odnos pacijenta i medicinskog osoblja, posebno odnos pacijenta i liječnika tema je koja zaokuplja sve više pozornost teoretičara, istraživača i praktičara. Ovom problemu i temi pristupaju i zdravstveni djelatnici ali i komunikacijski stručnjaci (1). S obzirom na različita znanstvena područja kojima pripadaju zdravstvo i komunikacija ova tema postala je interdisciplinarna odnosno potrebu sagledavanja problematike iz perspektive najmanje dva znanstvena područja.

Teorijski pristup modela zaokružit ćemo razmatranjem dva osnovna modela jednosmjerni i dvosmjerni, a iz njega ćemo izvoditi i asimetrični i simetrični dvosmjerni model (2). Komunikacijska znanost u svom širokom pristupu proučavanja definira razine i oblike komuniciranja. Razine komunikacije su intrapersonalna, interpersonalna, skupna i masovna komunikacija. Svaki se oblik komunikacije može oslanjati na različite kodove te može biti izložen različitim kanalima. Oblici komunikacije, koje razmatramo, mogu biti: usmena, pisana i neverbalna komunikacija (3). Ove oblike komuniciranja razmatrat ćemo kroz interpersonalnu komunikaciju.

Prema bolničkoj praksi Sjedinjenih Američkih Država, medicinsko osoblje je organizirano tijelo licenciranih liječnika i drugih pružatelja zdravstvene skrbi koje je definirano i dopušteno zakonom i za pružanje medicinske pomoći u bolnici ili zdravstvenoj ustanovi. Dakle, u širem smislu gledano medicinsko osoblje obuhvaća širi okvir pružatelja medicinskih usluga. No, u ovom radu pod medicinskim osobljem primarno ćemo govoriti o medicinskim sestrama i istražiti njihov odnos prema ključnim dionicima a u središtu istraživanja bit će pacijenti.

Pacijent u ovom radu, u najužem smislu definicije je korisnik zdravstvene usluge. To su osobe koje su 
iz različitih razloga primljeni na medicinsku skrb ili liječenje.

\section{RAZVOJ ODNOSA MEDICINSKOG OSOBLJA I PACIJENTA}

Komunikacija u medicini, vrlo je složena, međusobno isprepletena i u njoj sudjeluju liječnici, medicinske sestre/tehničari, fizioterapeuti i drugi subjekti komunikacije. Središte ove komunikacije je odnos liječnika i pacijenta. S druge strane praksa pokazuje da s pacijentima najviše komunikacije ostvaruju medicinske sestre i to je središte primjene komunikacije u zdravstvu.

Povijest odnosa u medicini mijenjao se kroz stoljeća još od Hipokratova vremena. U svim tim razdobljima medicinsko osoblje, prije svega liječnik je imao izraziti ugled u društvu. Liječnik je bio taj koji je davao savjete, imao je očinski odnos prema pacijentima, a takav se odnos naziva paternalizam (4). Takav, strogo racionalan odnos, najduže se zadržao u medicini gdje je pacijent samo slušao liječnika, pridržavao se njegovih savjeta liječenja, uz rijetka, bojažljiva, pitanja koje bi pacijent upućivao liječniku. To je bilo vrijeme silna raskoraka između znanja pacijenta u odnosu na liječnika, tako da je prva i posljednja instanca u liječenju bio liječnik, nije bilo posrednika. Pacijent je u ovom odnosu bio u podređenom položaju, jer je o svemu odlučivao liječnik. Sredinom prošlog stoljeća, naglim razvojem znanosti, medicine i informatizacijom društva situacija se stubokom promijenila (5).

Danas je većina pacijenata informatički i informacijski obrazovana, i za simptome svoje bolesti često traže odgovore preko tražilice na internetu. Internet i novi mediji su postali posrednici između pacijenta, liječnika i medicinskog osoblja. Pacijenti dolaze u bolnicu ili liječniku sa puno zdravstvenih informacija, često iz neprovjerenih izvora sa interneta, sa puno pitanja, tako da liječnik, koliko god dobro obavljaju posao koji se odnosi na samo liječenje pacijenta, mora biti spreman i na kvalitetnu komunikaciju. U tome se ogleda bit novog odnosa liječnik-pacijent koji danas nije povijesno paternalistički, već je suradničko-partnerski odnos.

\section{MODELI, RAZINE I OBLICI KOMUNICIRANJA U ZDRAVSTVU Modeli komuniciranja}

Povijesno gledano, komunikacija pa i grana komunikacije odnosi s javnošću razvijaju se kroz četiri modela koja se mogu promatrati i kao povijesni razvitak propagande i javnog informiranja. Ta klasifikacija potječe od američkih znanstvenika J. E. Gruniga i T. Hunta. Prema njima postoje četiri povijesna, ali i danas aktualna i u praksi primijenjena modela komuniciranja između različitih subjekata u komunikaciji. To su (6):

1. model tiskovne agenture i publiciteta,

2. model javnog informiranja,

3. dvosmjerni asimetrični model, $\mathrm{i}$

4. dvosmjerni simetrični model.

S medicinsko-komunikacijskog aspekta promatrat ćemo navedene modele $\mathrm{u}$ ta dva pristupa komunikacije, ali prije toga dat ćemo osnovno značenje modela.

\section{Model tiskovne agenture i publiciteta (The Press Agentry/Publiciti Model).}

Tehnike tiskovne agenture i publiciteta počele su poprimati važnost i u brojnim kampanjama, posebno u posljednjem desetljeću devetnaestog stoljeća. Stvaranje publiciteta u medijima putem press agenata (komunikacijskih i PR stručnjaka) i danas je model komuniciranja u društvu ali i zdravstvu(7).

\section{Model javnog informiranja}

Model informiranja razvija se kao svijest o otvaranju komunikacije organizacije prema novinarima i medijima. Jednosmjerni model javnog komuniciranja organizacije prema javnosti, prema istraživanjima, još uvijek je vrlo primjenjiv u praksi svih institucija pa i onih zdravstvenih.

\section{Dvosmjerni asimetrični model}

Američki profesor Edward Bernays bio je vodeći protagonist dvosmjernog asimetričnog modela komuniciranja, kao i jedan od onih koji je pomagao da se razvije dvosmjerni simetrični model. Ovaj teoretičar i praktičar komunikacija smatrao je da je i manipulacija dopuštena u uvjeravanju javnosti. Smatra 
se da je u praksi najviše korišten i da ga primjenjuju sve institucije.

\section{Dvosmjerni simetrični model}

Razvojem dvosmjernog simetričnog modela komuniciranja javljaju se i suvremeni odnosi organizacije i njene javnosti. To je vrijeme širenja globalne informacije koje započinje sredinom 1960-tih godina. Od tada odnosi (komunikacija) postaju sve složeniji i značajniji. U dvosmjernom simetričnom, u odnosu na treći asimetrični model još jače su naglašene povratne (feedback) veze.

Razmatrajući povijesni razvoj odnosa liječnik ili medicinsko osoblje-pacijent nedvojbeno je da paternistički odnos liječnika ili medicinskog osoblja i pacijenta ukazuje na model jednosmjerne komunikacije, više model informiranja. Brojni su primjeri stjecanja publiciteta zdravstvenih ustanova što, također implicira primjenu jednosmjernog pristupa i modela publiciteta. S druge strane suradničko-partnerski odnos ukazuje na jedan drugačiji pristup komunikaciji tj. Asimetrični ili simetrični model. Istraživanjem modela unutar ove komunikacije jasno će otkriti koji pristup je dominantniji, asimetričan ili simetričan.

\section{Razine komunikacije}

Pojmu razina komuniciranja autori pristupaju na različite načine. Neki koriste termin vrste, razine, drugi treći tipovi, načini, oblici komuniciranja itd. No, bez obzira na različit terminološki pristup, ti termini s obzirom na kvantitetu komunikacijskog procesa, vrijeme i način potreban za povratnu informaciju (feedback) sugeriraju četiri razine:

1. intrapersonalna komunikacija,

2. interpersonalna komunikacija,

3. skupna komunikacija,

4. masovna komunikacija.

\section{Intrapersonalna komunikacija}

Vrsta je komunikacije koju osoba čini sama sa sobom. Dakle, osoba intrapersonalno komunicira kada o nečemu razmišlja, rješava (u glavi) neki problem, pravi plan aktivnosti itd.

\section{Interpersonalna komunikacija}

Osnovna jedinica komunikacije(8). Interakcija je ili međusobno djelovanje dviju ili više osoba licem u lice, uz mogućnost trenutačnog (za razliku od odgođenog) dobivanja povratnih informacija. Interpersonalna komunikacija može biti verbalna $i$ neverbalna.

\section{Skupna komunikacija}

Odvija u okviru jedne, dvije ili više skupina. S obzirom na tipove skupina možemo ih podijeliti na običajne, institucionalne i društvene. Osnovna odlika običajnih skupina njihova je ukorijenjenost u strukturu društva, jer se njima pripada samim rođenjem, a ne uključivanjem. Takve su skupine obitelj, pleme, kasta, etnička skupina i dr.

\section{Masovna komunikacija}

Pod ovim pojmom razumiju se izjave koje se javno, tehničkim distribucijskim sredstvima, izravno i jednostrano prenose širokoj publici. Dakle, masovne komunikacije uključuju masovne medije koje $\mathrm{P}$. Trowler(9) definira kao "metode i organizacije pomoću kojih specijalističke društvene skupine prenose poruke širokoj, socijalno mješovitoj i raspršenoj publici".

\section{Oblici komuniciranja}

U komunikacijskoj znanosti ovoj podijeli, također se pristupa na različite teorijske načine. No sublimirajući suštinu i karakter komunikacije, oblici komunikacije mogu biti: usmena, pisana i neverbalna komunikacija.

\section{Usmena komunikacija}

Karakterizira je razgovor u kojima je izgovorena riječ glavni kod komunikacije.

\section{Pisana komunikacija}

Komunikacije u kojima su sredstvo prenošenja poruke napisane riječi, nazivamo pisanim komunikacijama. Pisane komunikacije odvijaju se između osoba, unutar poduzeća ili između poduzeća i okoline, a mogu se izvoditi u papirnatom ili elektroničkom obliku. 
Pisano komuniciranje, za razliku od usmenog, ostavlja pisani trag u poslovnim aktivnostima. Bitna prednost pisanog komuniciranja je $\mathrm{u}$ tome što ostavlja dokument koji se može čuvati i koji služi kao dokaz u ostvarivanju prava, ili u međusobnom odnosu (poslovnih) partnera.

\section{Neverbalna komunikacija}

Neverbalna komunikacija odnosi se na sva namjerna i nenamjerna značenja koja nemaju oblik napisane ili izgovorene riječi. Neverbalna komunikacija obuhvaća elemente kao što su izraz lica, pogled, geste, odjeća i vanjski izgled, razdaljina među sugovornicima i ton glasa.

\section{KOMUNIKACIJA MEDICINSKOG OSOBLJA S KLJUČNIM JAVNOSTIMA}

Medicinske sestre u stalnoj su komunikaciji s ključnim dionicima, ciljnim javnostima tijekom radnog vremena. Ta komunikacija odvija se prema liječnicima, medicinska sestra prema medicinskoj sestri, medicinska sestra prema pacijentu, dalje prema pacijentu i rodbini skupno, i odvojeno prema rodbini, prema studentima, pa sve do medija u izuzetnim okolnostima. Komunikacijski odnos je složen. Traži jak komunikacijski kapacitet i stručan odnos. Medicinske sestre moraju imati komunikacijske vještine kao što imaju i kliničke vještine(10).

\section{Medicinska sestra-liječnik}

Posljednjih 40 godina, medicinska sestra polako prestaje biti podređena liječniku i njena uloga u zdravstvenoj skrbi nadilazi samo izvršavanje naredbi ordiniranih od strane liječnika. Postaje član interdisciplinarnog tima unutar svojih kompetencija. Brojni su razlozi doveli do toga, u prvom redu obrazovanje medicinskih sestara, a ono najvažnije mijenja se zdravstvena slika stanovništva. Vodeći javno zdravstveni problemi postaju kronične bolesti koje zahtijevaju drugačiji pristup u zdravstvenoj skrbi pojedinaca. Prema World Health Organization (WHO) kronične bolesti (11) predstavljaju izazov 21 stoljeća i pokreče dva nova modela: Model kronične njege i Okvir inovativne skrbi u kroničnim stanjima. Oba modela u fokus stavljaju informirane, motivirane pacijente, obitelj i zajednicu kojima podršku pružaju informirani i motivirani timovi u praksi.

Analizirajući modele komuniciranja između liječnika i medicinskih sestara dominantna je dvosmjerna komunikacija. Najčešći model je dvosmjerna simetrična. U izuzetnim oklonostima i liječnici i odjeli komuniciraju s vanjskom, eksternom javnošću putem medija pa tako ulaze i masovno komuniciranje. Sva tri oblika komunikacije primjenjuju se svakodnevno. Verbalna i neverbalna su dominantan oblik komuniciranja liječnik-medicinska sestra ali značajno je zastupljena i pisana komunikacija, posebno putem e-mail komunikacije.

\section{Medicinska sestra - pacijent}

Medicinske sestre komuniciraju s pacijentima vrlo intenzivno i svakodnevno, imajući u vidu da su pacijenti različiti po obrazovanju, kulturološkom, vjerskom, društvenom statusu, prijašnjim iskustvima itd. Ta činjenica upućuje na potrebu da se komunikacija mora voditi na učinkovit, brižan i profesionalan način.

Pacijent postaje aktivni sudionik u procesu liječenja, donosi odluku o predloženom dijagnostičkom i terapijskom postupku na temelju dobivenih informacija od strane zdravstvenog tima koji se skrbi o njemu. Medicinske sestre su 24 sata uz pacijenta i prve su s kojima će pacijent podijeliti svoje strahove, tražiti odgovore na brojna pitanja. Potrebno je prilagoditi veliku količinu informacija pacijentu kako bi bile razumljive. S druge strane obitelj i prijatelji žele biti dio tog procesa i zahtijevaju posebnu pozornost i vrijeme. Ovakav pristup predstavlja izazov za medicinske sestre jer osim medicinskog znanja mora poznavati osnovne komunikacijske zadatke $\mathrm{u}$ radu.

Tri su osnovna zadatka: 1. Uspostavljanje kontakta. To obuhvaća predstavljanje i oslovljavajte bolesnika s gdin. ili gđa. (ime ili prezime). Važno je u interpersonalnoj komunikaciji osobu gledati izravno u oči i biti pozitivan. Također je važna neverbalna komunikacija. Komunikacija treba biti otvorena i dvosmjerna. Potrebno je dati kratko pojašnjenje onoga što radite za bolesnika i zašto. Govoriti jasno i razgovjetno. 2. Emocionalna reakcija može biti višestruka. 
Očekujte da osoba ne zna na što mislite, ne razumije medicinske termine, ne poznaje bolnicu i dr. Bolesnik smije biti jednostavan, neobrazovan, neupućen, dezorijentiran. No i takav je odgovornost medicinskog osoblja. Važno je razviti osobnu i komunikacijsku empatiju. Vi ste profesionalac i morate imati više osjećaja za i od bolesnika. 3. Način komuniciranja je još jedan izazov za medicinske sestre. Komunikacija se ne izvodi iz pozicije roditelja. Medicinsko osoblje tj. medicinske sestre moraju paziti na neverbalne $\mathrm{i}$ paraverbalne znakove, govoriti afirmativno - slušam bolesnika, $i$ iskazati spremnost za pomoć.

Vremenom medicinsko osoblje bolje upoznaje svog sugovornika tj. pacijenta. Taj odnos može dovesti do novog povjerenja, prihvaćanje savjeta kao i sudjelovanja u provedbi terapije. Krajnji cilj tih odnosa je bolje zdravlje i zadovoljstvo kako pacijenta tako i medicinskog osoblja.

Analiza modela komuniciranja između medicinskih sestara i pacijenta ukazuje na dominantnu dvosmjernu komunikaciju. S obzirom na odnos i činjenicu da medicinska sestra ne zamjenjuje liječnika kad je u pitanju proces liječenja, tj. ne preuzima ulogu liječnika taj dvosmjerni odnos često je asimetričan ponekad i jednosmjeran. Medicinske sestre razvijaju i dvosmjerni simetrični odnos kad je u pitanju odnos, komunikacija i nadležnosti medicinskih sestara. Dominantna razina komuniciranja je interpersonalna, a oblik usmena, verbalna i neverbalna komunikacija.

\section{Medicinska sestra - rodbina pacijenta}

Medicinske sestre često su u komunikaciji s rodbinom pacijenata. Ta komunikacija izazovna je samo na razini potrebnih informacija koje treba razmijeniti. Odnos je profesionalan. Medicinske sestre žele imati roditelje i rodbinu uključene u proces liječenja na način da pacijent prihvaća pristup liječenja i odluke koje zajednički donose s liječnikom i medicinskim timom. Kod ove razine najistaknutija je interpersonalna, osobna komunikacija. Verbalno, usmeno i neverbalno komuniciranja kao oblik je najzastupljenije.

\section{Medicinska sestra-medicinska sestra}

Odnos između medicinskih sestara unutar odjela je hijerarhijski posložen. Svaki dan radi se plan zdravstvene njege koji izrađuje voditelj tima i odgovoran je za njegovu provedbu. Izvršene aktivnosti moraju se dokumentirati. Voditelji timova odgovorni su glavnoj sestri. Čimbenici koji utječu na primopredaju službe mogu biti: komunikacijski stil medicinske sestre, iskustvo i stečeno znanje, kontinuitet zdravstvene njege, uključenost pacijenta u skrb, jesu li medicinske sestre stalni član tima ili su na zamjeni, priroda bolesti pacijenta.

Model komuniciranja medicinska sestra-medicinska sestra je dvosmjerni. Hijerarhija sugerira da ima primjene i jednosmjerne komunikacije. Dominira interpersonalna razina i verbalno-neverbalni oblik komuniciranja.

\section{Medicinska sestra i drugi dionici}

Komunikacija između medicinskih sestara i ostalih dionika godinama je predmet proučavanja brojnih autora. Istraživane su prepreke za učinkovitu komunikaciju u zdravstvenoj njezi i utjecaj učinkovite komunikacije na zdravlje pacijenata. Nastoje se utvrditi moguća sredstva za poboljšanje učinkovitosti komunikacije. Glavni inhibirajući faktori učinkovite komunikacije u prvom redu osobne karakteristike kao što je strah, nisko samopouzdanje, anksioznost, razina pismenosti, prijašnja iskustva i s druge strane nedostatak komunikacijskih vještina, empatije, ne mogućnost postavljanja granice, vještine slušanja, okruženje. Učinkovita komunikacija ima pozitivan učinak na zdravstveno stanje pacijenta $\mathrm{i}$ njihov oporavak, a loša komunikacija ima negativan utjecaj na zdravstveno stanje. Upotreba učinkovite komunikacije nema samo pozitivan utjecaj na pacijente već i na zdravstvene profesionalce čineći ih zadovoljnijim na poslu, manje izložene stresu što ima jak utjecaj na zdravlje.

\section{ZAKLJUČAK}

Svjetska zdravstvena organizacija definirala je kvalitetnu komunikaciju kao jednu od pet vještina neophodnih za zdrav život (12). Tako je komunikaciji dano na važnosti kada je u pitanju zdravlje 
i medicina. S druge strane pitanje komunikacije $\mathrm{u}$ zdravstvu je pitanje koje tek zahtijeva sustavno istraživanje i definiranje najboljih oblika, razina i modela komuniciranja (13).

Dominantne modele komuniciranja biomedicina može preuzeti iz društvenih znanosti. Dominantna su dva modela: jednosmjerni i dvosmjerni koji se opet dijele na jednosmjerni model publiciteta i informiranja, a dvosmjerni na asimetrični i simetrični model. Komunikaciju u zdravstvu, točnije odnos medicinskog osoblja i pacijenta, analizirali smo i s razine komuniciranja. Dominiraju četiri oblika: intrapersonalna, interpersonalna, skupna i masovna komunikacija. Kod oblika komunikacije susrećemo verbalnu i neverbalnu komunikaciju te pisanu komunikaciju.

Liječnici i medicinsko osoblje tj. medicinske sestre na razini komuniciranja dominantno komuniciraju interpersonalno sa svim dionicima u procesu komunikacije pa tako i s pacijentima. Kako je poznato da interpersonalnoj komunikaciji prethodi intrapersonalna komunikacija onda je i ova razina vrlo naglašena u komunikaciji. Dnevno se skupno komunicira u timu tako da je i ova razina komunikacije jako važna u ovim odnosima.

Analiza oblika komuniciranja ukazuje na primjenu sva tri oblika. Vremenski gledano usmena i neverbalna komunikacija su dominantne. Koliki je utjecaj jednog ili drugog oblika, to treba biti predmet novih istraživanja. Nesumnjivo je kako su oba oblika važna u komunikaciji medicinska sestra-liječnik-pacijent-roditelji. Svi dionici komunikacijskog procesa komuniciraju i pisanim putem tako da se primjenjuje i treći oblik komuniciranja.

Modeli, razine i oblici komuniciranja medicinskog osoblja s pacijentima, roditeljima pacijenata i drugim dionicima je nedovoljno istraženo područje u Republici Hrvatskoj. Njemu treba pristupiti sustavno kroz najznačajnije znanstvene metode istraživanja. Takvi rezultati pomoći će medicinskim institucijama, menadžmentu ali i medicinskom osoblju pronalaženje najboljih i optimalnih modela, razina i oblika komuniciranja, a to će pridonijeti boljoj skrbi i zdravlju u cijelosti.

\section{LITERATURA}

1. Brkljačić M. Etički aspekti komunikacije u zdravstvu medicina. Fluminensis 2013;49(2):136-143.

2. Kunczik M, Zipfel A. Uvod u znanost o medijima komunikologiju. Zagreb: FES, 2006.

3. Rouse M, Rouse S. Poslovne komunikacije Kulturološki i strateški pristup. Zagreb: Masmedia, 2005.

4. Braš M, Đorđević V, Miličić D. Odnos liječnika i bolesnika. u: Đorđević V, Braš M. Komunikacija u medicini-Čovjek je čovjeku lijek. Zagreb: Medicinska naklada, 2001. str. 18.

5. Hozo I. i sur. Internistička propedeutika s vještinama komuniciranja u kliničkoj medicini. Split: Hrvatsko gastroenterološko društvo-ogranak, Split, 2013.

6. Grunig J, Hunt T. Managing of Public Relations. Belmont: Thomson-Wadswortgh, 1984.

7. Tomić Z. Odnosi s javnošću-teorija i praksa. Zagreb-Sarajevo: Synopsis, 2016.

8. Tubbs S. Human Communication-Principles and Contexts. New York: Mc Graw Hill, 2010.

9. Haralambos M, Holborn, M. Sociologija teme i perspektive. Zagreb: Golden marketing, 2002.

10. Standard 1. Standards for Establishing and Sustaining Health Work Environments, American Association of Critical Care Nurses, 2005.

11. World Health Organization. Dostupno na http://www.who.int/ncds. (Preuzeto 9.4.2018).

12. World Health Organization Outbreak Communication Planning Guide. Dostupno na: http://www.who.int/ihr/ elibrary/WHOOutbreakCommsPlanngGuide.pdf. (Preuzeto 2.4.2018). 


\title{
MODELS, LEVELS AND FORMS OF COMMUNICATION OF MEDICAL PERSONNEL AND PATIENTS
}

\author{
Sandra Karabatić, Tanja Zovko, Latinka Basara \\ Clinic for Pulmonary Diseases Jordanovac, University Clinical Centre Zagreb, 10000 Zagreb, Croatia
}

\begin{abstract}
The complex relationship between the patient and medical personnel has a long history. The relationship between the patient and medical personnel, especiallythe patient-doctor relationship is a topic that occupies increasing attention of theoreticians, researchers and practitioners. Health professionals and communication experts also address this issue and topic. Considering different scientific disciplines of healthcare and communication, this topic has become interdisciplinary so there is a need to consider this issue from the perspective of at least two scientific disciplines. Today, the communicational aspect of these relationships determines the quality of health care as well as the final outcome of treatment. A special aspect of work is devoted to in concretocommunication of medical personnel with patients but also other stakeholders who are of outmost importance for the understanding of this complex process as well as the success of communication. In this work, medical personnel will be defined, in the strict sense, as nurses. Their relationship with patients is the central focus of this work. The objective of the work is to analyze the levels, forms and models of communication of medical personnel with the patient and other target audiences or stakeholders.

Key words: communication, models and forms of communication, medical personnel, patient
\end{abstract}

Correspondence:

Sandra Karabatić, MSN.BSN.RN

E-mail: udruga.jedra@gmail.com 